\title{
O QUE É REPRESENTAÇÃO POLÍTICA? UMA INTRODUÇÃO AO TEMA ${ }^{1}$
}

\author{
WHAT IS POLITICAL REPRESENTATION? AN INTRODUCTION TO THE SUBJECT
}

\author{
PROF. DR. ANDRÉ RICARDO DIAS SANTOS ${ }^{2}$
}

\author{
INSTITUTO FEDERAL DO SERTÃO PERNAMBUCANO
}

\begin{abstract}
RESUMO: Este trabalho visa abordar de forma direta e introdutória as origens da noção de representação na cultura ocidental. Do seu surgimento nos espaços da arte a sua apropriação pela cultura jurídica, a representação chega à política como forma de institucionalização da soberania. Com a representação política vemos a consolidação do Estado moderno e da noção de soberania - em seu marco hobbesiano. Hoje, em meio ao aparente declínio de sua eficácia, crescem os debates em torno do ressurgimento de outras formas de mediação ou institucionalização da vida nas sociedades complexas. Sendo assim, nos debruçaremos sobre a história conceitual da representação política: seu percurso instrumental enquanto garantia do poder soberano; e sua dimensão propriamente filosófica: o problema da apresentação das vontades pelos mecanismos de mediação.
\end{abstract}

Palavras-chave: Representação, poder, soberania.

ABSTRACT: This paper aims to address in a direct and introductory way the origins of the notion of representation in the Western culture. From its emergence in the spaces of art and its appropriation by legal culture, representation comes to politics as a form of institutionalization of sovereignty. With political representation, we see the consolidation of the modern State and the notion of sovereignty - in its Hobbesian framework. Today, amid the apparent decline in its effectiveness, there is growing debate over the resurgence of other forms of mediation or institutionalization of life in complex societies. Thus, we will focus on the conceptual history of political representation: that is, its instrumental path, as a guarantee of power; and its properly philosophical dimension: the problem of the presentation of wills by the mechanisms of mediation.

Keywords: Representation; power; sovereignty.

Neste trabalho pensamos a representação em sua relação de interdependência com o estatuto teórico da soberania. Para tanto, nos cabe abordar a questão não apenas em sua relação simbiótica com o poder soberano, mas também na sua difícil relação com o poder constituinte. As

\footnotetext{
${ }^{1} \mathrm{O}$ presente artigo origina de capítulo da tese de doutorado do autor, intitulada "Estado de exceção e Estado democrático de direito: violência e poder no pensamento de Walter Benjamin” (No prelo, 2019).

2 Doutor em Filosofia Política pela Universidade Federal da Paraíba. Estágio doutoral pela Università degli Studi di Padova.
} 
referências encontradas sobre o tema buscam contemplar a gama de conceitos que acompanha as mudanças semânticas da história da representação política. Em meio a esta história, destaca-se a reviravolta pela qual a problemática passou em meados do séc. XIX, desde os desdobramentos da Revolução industrial e no contexto da consolidação dos Estados republicanos na América e na Europa. Entretanto, compreendemos que foi na metade do século XX que o problema assumiu os contornos da crise que nos deparamos hoje.

Hanna Pitkin (2017, 2006 - respectivamente), nos estudos de 1967 e 1989, define a representação parlamentar (PITKIN, 2017) pela ação de um make present again. Em linhas gerias, diríamos que em política representar é a atividade de dar voz aos cidadãos, a suas opiniões e demandas, orientada pelas concepções congruentes com a figura do representante por eles eleito. Neste sentido comum, representar se assemelharia a uma assistência de caráter processual, devido a suas funções frente ao Estado e suas instituições. Ali realizar-se-ia uma convergência de uma parte geral, o povo, com um particular, a burocracia estatal. Normalmente circunscrita à esfera pública, - e aqui deixamos de lado a separação entre direito privado e público em nome do seu significado geral -, a representação deixa a todos a liberdade do trabalho e da vida privada enquanto um grupo minoritário debate - mas sobretudo decide - os rumos da vida pública e privada.

Antes deste significado geral, o correlato semântico mais próximo da aplicação política do mecanismo representativo encontra-se na figura do advogado e nas bases gerais do direito romano. No entanto, mesmo nesta origem não podemos estabelecer uma correlação direta com a semântica atual do termo. Não só o advogado não estava investido das prerrogativas que o caracterizam no direito moderno, como ali a função de representar se assemelha mais a um tipo de auxiliar de nobres, clérigos e senhores, estes que, de fato, portavam a vox e a decisão - ou, por vezes, a regra. Isto, até chegarmos à política moderna, quando o termo representação política assume as características que o definiriam, pela forma parlamentar de autuação de uma classe política, vemos que o campo dos interesses norteara a atuação de grupos e classes sociais em busca de uma organização da vida política que estivesse à frente da complexidade do mundo mercantil e industrial. E, posteriormente, esta lógica estará à frente de todos os desdobramentos políticos em torno da questão.

No trato do tema, a literatura contemporânea parece convergir entre a historiografia conceitual, a crítica política e as elaborações teóricas de futuro - ou de uma política pósrepresentação. Neste sentido, grande parte da bibliografia atual apresenta vários resultados acerca 
de estudos sobre a ideia de formas de democracia direta ${ }^{3}$. Neste caso, longe de proferir um retorno pré-socrático às origens de um espaço público mediado pelas decisões assembleianas, as razões da técnica e da ciência contemporâneas inflam as possibilidades de uma mediação do espaço coletivo (alguns referem-se a um pós-público, na tentativa de afastar o quanto que o conceito de público guarda de laço estatal) sob orientação ideológica anti-sistema ou anti-capitalista. Neste campo da crítica, levanta-se a questão do sufrágio, da representação de minorias (YOUNG, 2006), da corrupção estrutural do Estado, das formas de participação política não-eleitorais: em suma, tratase de correntes com divergências teóricas e políticas, porém debruçadas sobre a grande crise da representação que ganhou contornos próprios neste início de século.

O fato é que a representação se tornou objeto de análise da ciência política e um problema do pensamento político. Embora o espectro de conceitos e problemas que giram em torno da questão ultrapasse sua "circunscrição" - o problema da criação da lei pelo parlamento, o problema da mediação das vontades, e mesmo a questão da soberania - estes últimos conformam o próprio conceito de representação política.

Em continuidade, podemos dizer ainda que há o que podemos chamar de um vocabulário próprio da esfera da representação. O representante, os eleitores, o sufrágio, a ideia - e o grau - de participação política etc (PITKIN, 2006). Ainda, sabemos que a moderna sociedade industrial vez surgir formas de representação não experimentadas pela primeira leva de pensadores liberais. É possível falarmos em representação política participativa ou representação direta, por exemplo ${ }^{4}$.

\section{O QUE É REPRESENTAÇÃO POLÍTICA? HISTÓRIA E CRÍTICA DE UM CONCEITO}

Hanna Fenichel Pitkin, no clássico artigo de 1989 Representation, esboça uma pequena história do conceito de representação. No contexto do surgimento do termo, Pitkin aponta os elementos que estão às voltas da consolidação do conceito de representação na esfera política:

A evidência etimológica não é inteiramente clara, mas sugere que toda a família de termos [repraesentare] parece ter sido aplicada ao Parlamento [ver a seguir] como um todo. E os significados estão obviamente em transição,

\footnotetext{
3 Além das referências às possibilidades de formas diretas para o exercício de regimes políticos democráticos, encontramos referências a outras formas de pensar uma crítica à representação. Tal como a ideia de formas nãoeleitorais de representação, que configuram uma crítica interna à categoria política da representação. (APTER, David. "Notes for a theory of nondemocratic representation", entre outros).

${ }^{4}$ MANSBRIDGE, Jane. "Representation Revisited: Introduction to the Case Against Electoral Accountability", dentre outros.
} 
do antigo "pôr-se em lugar de outros", pela via da substituição, para algo como "atuar para outros". Os termos parecem ser utilizados, primeiramente, como uma expressão de - e como uma demanda por autoridade, poder e prestígio. (PITKIN, 2006, p. 27).

Vejamos, pois, uma brevíssima história da já curta historiografia acerca do conceito, sobretudo, pelas letras de Hanna Pitkin e Hasso Hofmann e teóricos do pensamento político contemporâneo. Até chegar ao tema da representação política, a autora expõe as imbricações gerais da ideia histórica de representar (alguém, algo etc) até a função política que a expressão assume. Sobre uma origem deste significado na vida pública no ocidente, esclarece que:

Embora os gregos antigos tivessem várias instituições e práticas às quais aplicaríamos a palavra "representação", eles não tinham palavra ou conceito correspondente. O termo é de origem latina, embora também em latim seu significado original não tivesse a ver com agência, governo, ou quaisquer instituições da vida romana que poderíamos considerar como exemplos de representação. A palavra latina repraesentare significa "tornar presente ou manifesto; ou apresentar novamente. (...) Pode significar "desempenhar imediatamente" e mesmo "pagar em dinheiro". Não tem a menor relação com pessoas representando outras pessoas, ou com o Estado romano.(PITKIN, 2006, p. 17).

E é curioso observar como ao longo do período forte da primeira era dos impérios, o termo assume uma investidura transcendente, vez que, "na idade média, a palavra é estendida na literatura da cristandade a um tipo de encarnação mística":

\footnotetext{
Mas sua real expansão começa no século XIII e no início do século XIV, quando se diz com frequência que o papa e os cardeais representam a pessoa de Cristo e dos apóstolos (...). Ao mesmo tempo juristas medievais começam a usar o termo para a personificação da vida coletiva (...). A ênfase está na natureza fictícia da conexão: não se trata de uma pessoa real, mas de uma pessoa apenas por representação (persona non vera sed repraesentate). (PITKIN, 2006, p. 18).
}

Do alemão ao inglês, passando pelo francês no século XIV, o termo passa a ser utilizado em contextos que já o aproximam da dimensão assumida através dos séculos seguintes; representar alguém, tal qual "um empregado representando a pessoa de seu senhor", passando pela dimensão pictórica (Séc. XV) junto aos verbos retratar, figurar etc. Todavia, vimos que representar tal como “tomar ou ocupar o lugar de outra pessoa, substituir", só encontra uso a partir do século XVI.

Sua face política surge com as funções administrativas desenvolvidas no contexto de maior complexidade assumida pela função política institucional. Por volta do séc. XV, no contexto inglês, "cavaleiros e burgueses" passaram a desempenhar de maneira conjunta ações próprias junto 
ao Parlamento, até serem identificados e incorporados por este: "Repentinamente, havia apenas o Parlamento para governar a nação e para escolher o líder do governo, em nome da nação”. Ainda neste contexto, no entanto, estes indivíduos "eram vistos como os servidores ou delegados". Com maior solidez e visibilidade em suas funções, "começaram a se ver, e a serem vistos, como aqueles que "vinham pela comunidade do lugar". Só ainda mais tarde, no início do século XVII", a aura mística da representação política adquire contornos de representação soberana, com a força do pensamento absolutista que, para sua manutenção como poder, também imprimia a ideia da representação de todos - com exceções - no parlamento, e que o governante soberano era, na realidade, o equivalente deste todo. Esta equivalência espectral fora aceita como o todo unificado pelas referências míticas da representação, diríamos, em termos judaico-cristãos, como encarnação do eleito. Na prática, neste momento histórico, um poder de classe se consolidava, pela aceitação dos cavaleiros ou burgueses como representantes daquelas comunidades.

É no Leviatã (1651) que de fato encontramos o que viria a ser a primeira referência de cunho especulativo sobre a representação na história do pensamento político. Na obra, é sabido pela teoria política que Hobbes esboça a ideia da representação pela via formalística na perspectiva de uma forma legal, "especificamente em termos de autorização: um representante é alguém que recebe autoridade para agir por outro, quem fica então vinculado pela ação do representante como se tivesse sido a sua"(PITKIN, 2006, p. 32). Ainda com referência a Hobbes, a autora traz o trecho do volume III da obra, em que o filósofo defender a representação quando a coloca na sua relação indispensável na arquitetura estatal:

Diz-se que um Estado foi instituído quando uma multidão de homens concordam e pactuam, cada um com cada um dos outros, que a qualquer homem ou assembleia de homens aquém seja atribuído pela maioria o direito de representar a pessoa de todos eles (ou seja, de ser seu representante), todos sem exceção, tanto os que votaram a favor dele como os que votaram contra ele, deverão autorizar todos os atos e decisões desse homem ou assembleia de homens, tal como se fossem seus próprios atos e decisões, a fim de viverem em paz uns com os outros e serem protegidos dos restantes homens. (HOBBES, 1983, p. 107)

Do ponto de vista procedimental, Burke é citado largamente (obras de 1770; 1774) ${ }^{6}$ como um dos primeiros teóricos da representação no parlamento, com sua teoria da independência em

\footnotetext{
${ }^{5}$ Em nota, diz Pitkin (ibid, p. 21): "Existe uma variação considerável no que se refere ao período em que os membros do Parlamento pensaram em si mesmos, pela primeira vez, atuando por toda a nação. Adiante, afirmar que, de qualquer modo, tal desenvolvimento se dá entre os séculos XV e XVIII, com forte origem no direito romano e nas doutrinas medievais de concepção mística, assumidas pelos parlamentos e governantes num contexto de secularização da ordem e do poder teológicos”.

${ }^{6}$ BURKE, Edmund: "American Taxation" e "Speech to the Electors of Bristol”, respectivamente.
} 
termos de representação, que se expressa em termos tais, por exemplo, da obra do próprio autor (1774):

O Parlamento não é um congresso de embaixadores de interesses diferentes e hostis, cujos interesses cada um deve assegurar, como um agente e um defensor, contra outros agentes e defensores; mas o Parlamento é uma assembleia deliberativa de uma nação, com um interesse, o da totalidade - em que nenhum propósito local, nenhum preconceito local, deveria guiar, exceto o bem comum, resultante da razão geral da totalidade. Você escolhe um membro, de fato; mas quando você escolhe-o, ele não é membro de Bristol, mas é um membro do Parlamento. (BURKE, 2012, s/p).

Neste caso, o representante é escolhido por suas características intelectuais e morais (e escolhido pelos “melhores”, daí sua crítica ao sufrágio universal), e a partir delas deve exercer um governo da razão e do melhor para o interesse geral (e não particular): “o governo é uma questão de razão, não de vontade".

O liberalismo na América e o utilitarismo no solo inglês tratariam de ampliar os horizontes políticos da representação. De caráter fortemente individualista, esta vertente trataria de dar vOz a uma multidão de homens burgueses que experimentavam os novos direitos e poderes advindos da nova era econômica. Defenderiam a prática de governo representativo, tomado como um instrumento equivalente à prática da forma direta de participação democrática, devido ao contingenciamento causado pela ideia de uma reunião assembleiana pública, vista como inviável nas sociedades da nascente vida urbana. No mundo no qual a novidade dos negócios fazia transacionarem aqueles novos cidadãos - burgueses e proprietários de toda ordem - a organização política e econômica se mostrara imprescindível para o bom desenrolar das relações (igualmente de toda ordem). Para um pensador utilitarista como John Stuart Mill, no sistema de mediações que resulta necessário à crescente complexidade institucional, o papel do legislador direto é, paulatinamente, substituído pela via eletiva do parlamento legislativo, que acompanha em seu surgimento a criação de um instrumental burocrático que ampare institucionalmente sua atuação representativa.

A representação republicana ganha forma a partir de então, e a pretensão de universalismo da lei assume a busca pelo espelhamento das formas objetivas de interesse público do parlamento nas instituições e ações do Estado. Este esquema não deixaria de ser assegurado pela captura (tal a problemática do direito natural) de um poder do indivíduo, vez que este "não é o melhor juiz do seu próprio interesse”. Seguindo a trilha da tradição política do séc. XVII, sabemos que Rousseau 
adotaria a mesma posição através da sua ideia de "vontade", esta, porém, gerida por um tipo de auto-governança "expressa em participação direta".

Restou para os séculos seguintes de história social a compreensão da continuidade temporal e política entre ancien règime absolutista e a revolução burguesa europeia, já observada por Tocqueville ${ }^{7}$. Segundo o autor, podemos dizer que a liberdade política moderna se baseia na ilusão de seu exercício pelo voto, ao "escolhermos o próprio patrão", isto porque logo após o ato de eleição retornamos à cadeia de circulação da submissão e da servidão. Nisto implica, ainda, o problema da responsabilidade política (ou a recusa à esta responsabilidade) inerente ao ato de delegação das responsabilidades individuais que perfazem o coletivo. Este distanciamento da decisão, hoje, nos volta pela redução da participação em favor do exercício dedicado do trabalho e do consumo.

Apesar de Rousseau, nos séculos seguintes pouco se questionou a respeito da legitimidade da representação. Para Pitkin, "apenas em décadas recentes alguns pensadores novamente começaram a questionar pressupostos (...) que continuavam a desafiar a própria ideia de representação". Dos ideais socialistas, anarquistas e liberais (como em Hannah Arendt), a história posterior às revoluções do século XVIII viu a crise da política moderna passar pela questão da representação:

Esses pensadores têm sugerido que a participação no poder público e a responsabilidade podem ter um valor intrínseco e não apenas instrumental, necessário, portanto, ao bem da vida e ao pleno desenvolvimento dos seres humanos. Eles têm sugerido que apenas um povo ativo e com envolvimento político é livre e que as instituições representativas, inicialmente projetadas para abrir o domínio público para o povo comum anteriormente excluído, têm, de fato, servido para desencorajar a cidadania ativa. (PITKIN, 2006, p. 42).

Inferimos que a letargia política da função democrática moderna resulta, sobretudo, do fechamento do horizonte democrático na atividade do parlamento, entre a agência de interesses privados ou a liberdade dada ao sujeito "usurpador da liberdade popular periodicamente eleito". De forma que, como vimos em Hannah Arendt (1965), "[O povo] ou deve afundar numa 'letargia, precursora da morte da liberdade pública" ou deve "preservar o espírito de resistência" diante de qualquer governo que tenha eleito, já que o único poder que conserva é "o poder reserva da revolução".

\footnotetext{
7 Tocqueville, em "Da democracia na América" (1835).
} 
Agamben (2007, p. 102) defende que ao longo da modernidade a política passou por um processo histórico sistemático de esvaziamento de seus conceitos e categorias estruturantes. No entanto, ao comparar este processo a um "eclipse prolongado" chama a atenção mais uma vez para Arendt [1965], para quem parece não merecer atenção a disposição formalista em política de insistir no uso e significado dos conceitos clássicos. Entendendo que se trata de uma espoliação da potência de pensamento e ação do sujeito político, inserido no contexto das mutações das relações formais de troca social, deveríamos pôr em dúvida os próprios conceitos que representam o sujeito político (povo soberano, trabalhador, cidadão, etc). Daí poderíamos ver emergir as reais condições e o real estatuto do sujeito político, que excedem, apesar da exclusão, as estruturas criadas na modernidade para a conformação docilizada da política.

Ainda em termos de uma crítica à representação, caberia perguntarmos de que liberdade se fala aqui, vez que o povo que se faz sujeito político adquire sua existência formal se presentificando na representação e tem sua liberdade vinculada a tutela direta de direitos. Se quisermos pensar além de Hobbes, para o qual representar está em relação direta ao controle do estado de natureza, o imperativo da autonomia que se impõe ao sujeito político passa pela via da ação política. Por isso, a seguir apresentaremos algumas das principais discussões contemporâneas em torno do tema. Em comum, a crítica da representação chama a atenção para a já referida redução do sujeito político coletivo representado e, neste aspecto, chama à tomada de posição ativa no processo de uma verdadeira heteronomia política das diferenças, na esteira de um aprofundamento da democracia.

Segundo Duso, no clássico Representation, Hofmann (2007) faz uma tentativa de "mostrar como o conceito moderno de representação política apresenta uma lógica que impede a resolução/dissolução do agir representativo no espelhamento das vontades pré-existentes” (DUSO, 2012, p. 8-9). A respeito deste modelo de representação o autor persiste na abordagem do problema da apresentação das vontades individuais, ou, a dificuldade em presentificar ${ }^{8}$ o conjunto destas vontades que se dá frente a ação representativa sempre em função de um determinado conteúdo. Entendemos que esta questão, que remonta à Política de Aristóteles, encontra ao longo da história do pensamento político reelaborações da solução clássica que conecta o campo dos representantes à ideia de uma elite (intelectual ou econômica) capaz de apresentar as vontades pelo filtro do poder.

Em Duso (2012, p. 12), assim como em Pitkin (2006, p. 15) vimos que o conceito moderno de representação é conformado durante o período que vai da nowva scienza politica da

\footnotetext{
8 "Paradoxo inerente ao próprio significado da representação: tornar presente de alguma forma o que apesar disso não
} está literalmente presente" (PITKIN, ibid, p. 20). 
metade do século XVII ao período revolucionário francês, sob a "veste do direito natural". Sobre esta realização o autor lembra Schmitt, quando "revisando o conceito, identifica sua estrutura em um movimento que se faz presente mesmo que não verificável em uma realidade empírica, mas idealmente". Esta estrutura teórica estará na base da tematização das investigações sobre a teologia política.

Sobre a tematização do conceito em Schmitt, Duso nos traz Voegelin para lembrar que:

\begin{abstract}
Sua análise lúcida ajuda a entender a lógica do conceito de representação, mas também sua aporia. Todavia esta aporia não leva Schmitt a superação do conceito, resultado estritamente ligado àquele da soberania, e seu ato de radicalização resta incompleto, como nos mostrou Voegelin, que considera o jurista alemão prisioneiro da ciência política moderna e da lógica do conceito no qual o agir representativo é atribuído somente a quem exercita o poder, com a consequente perda do sentido transcendental da representação, que deveria, enquanto tal, coincidir com a práxis de todos. (DUSO, 2012, p. 10).
\end{abstract}

Daí que "a análise schmittiana não se dirige à superação do conceito moderno de representação". Dessa forma, o jurista alemão dispensa a possibilidade de, ancorando-se na aporia do conceito, apontar o salto teórico que fundamenta a possibilidade de pensar a política em termos de um alargamento de uma práxis democrática. Muito pelo contrário:

As principais teses políticas de Schmitt podem ser resumidas, grosso modo, da seguinte maneira: a política só se realiza como teologia política, porque a soberania se define como um poder transcendente e separado da sociedade - assim como Deus transcende o mundo, também o governante transcende a sociedade. Esse poder exercido pela vontade secreta do soberano o qual não só é o autor das leis, mas também não está submetido a elas e pode suspendê-las se assim quiser (como Deus suspende as leis naturais ao fazer milagres). Trata-se, portanto, de uma perspectiva religiosa a respeito do poder. (CHAUÍ, 2017, p. 207).

Duso (2012, p. 18) lembra que na forma política moderna que as constituições democráticas legitimam, "a relação estruturante que a representação estabelece com a constituição e pela legitimação do poder surge em toda sua evidência". Neste sentido, uma crítica à representação moderna passa inevitavelmente pela crítica do poder, em direção a uma forma de pensar a política democrática no sentido de alargar o horizonte de análise em busca de outras formas diversas daquelas determinadas desde a gênese dos conceitos políticos modernos.

Não se trata de encontrar modelos na tradição do pensamento e na realidade histórica distantes dos nossos dias, mas entender a não 
universalidade dos conceitos definidos como "modernos" e também a possibilidade de outros modos de pensar a política, e assim podermos confrontar a nossa realidade para além dos antolhos constituídos por conceitos considerados óbvios. A reflexão sobre a aporia da forma democrática e a dificuldade de utilizarmos os conceitos estabelecidos para entender processos em curso (...) leva a pensar junto como seria possível pensar a relação entre unidade e pluralidade, diversamente da unidade que caracteriza a forma política moderna. (DUSO, 2012, p. 11-12).

$\mathrm{Na}$ tentativa de pensar alternativas à forma política moderna:

Emergem uma série de categorias, sobretudo as de governo e pluralidade, que parecem úteis para pensar a política em uma direção do que se possa definir de uma forma federalista, com a advertência de que o termo federalismo, aqui, vai além do significado que o caracteriza e indica um modo diverso de pensar a política daquele determinado pelo arco conceitual que vai da soberania a constituição democrática. (DUSO, 2012, p. 15).

A continuidade da reflexão sobre a representação nos levaria a uma exaustiva discussão dos desdobramentos teóricos que o tema chama à discussão. Por exemplo, como lembra Accarino (1999, p. 65), já Hegel, em $1817^{9}$, observava que o exercício do voto não satisfazia "psicologicamente" a necessidade de atuação política da burguesia apta à participação política. Ali, a influência de uma atuação individual parecia insignificante frente ao monumental político administrativo e a força do poder soberano, restando de uma efetiva recusa social na participação do pleito eletivo, a necessidade de leis de persuasão e coerção para a participação pelo voto. Por isso, diz o autor: "A representação não fala só de política, também quando compreendida como uma decisão restritiva, mas inevitável, como a representação política: fala também da relação entre administração e política" (ACCARINO, 1999, p. 8). Diríamos mais: que a representação fala da relação entre política e vida.

\footnotetext{
${ }^{9}$ Hegel, "Princípios da filosofia do direito" (1820).
} 


\section{REFERÊNCIAS}

ACCARINO, Bruno. Rappresentanza. Bolonha: Mulino, 1999.

AGAMBEN, Giorgio. Estado de exceção. São Paulo: Boitempo, 2007

BURKE, Edmund. Speech to the Electors of Bristol, on His Being Declared by the Sheriffs Duly Elected One of the Representatives In Parliament for That City, on Thursday, the 3rd of November, 1774. In: The Works of the Right Honourable Edmund Burke, in Twelve Volumes. V. II. London: 2012, s/p.

CHAUI, Marilena. Sobre a violência. Col. Escritos de Marilena Chaui, vol. 05. Belo Horizonte: Autêntica, 2017.

DUSO, Giuseppe. "Ripensare la rappresentanza alla luce dela teologia politica". In: Quaderni Fiorentini. Florença: $n^{\circ}$ XLI, 2012, pp. 08-09.

HOBBES, Thomas, Leviatã ou matéria, Forma e Poder de um Estado Eclesiástico e Civil. São Paulo: Nova Cultural (Os Pensadores), 1983

HOFMANN, Hasso. Rappresentanza - Rappresentazione. Parola e concetto dall'antichità all'Ottocento. Milano: Ed. Giuffrè Editore, 2007.

PITKIN, Hanna. "Representação: Palavras, instituições e ideias". In: Revista Lua Nova. São Paulo: $\mathrm{n}^{\circ}$ 67, 2006.

Il concetto di rappresentanza. Milano: Rubetino Editore, 2017.

YOUNG, Iris Marion. Representação política, identidade e minorias. In: Revista Lua Nova, n67: São Paulo, 2006. 